Article

\title{
Hydrogen-Rich Water and Lactulose Protect Against Growth Suppression and Oxidative Stress in Female Piglets Fed Fusarium Toxins Contaminated Diets
}

\author{
Weijiang Zheng ${ }^{1}$, Xu Ji ${ }^{1}$, Qing Zhang ${ }^{1}$, Wenchao $\mathrm{Du}^{2}$, Quanwei Wei ${ }^{2}{ }^{\mathbb{C}}$ and Wen Yao ${ }^{1,3, *}$ \\ 1 Laboratory of Gastrointestinal Microbiology, Jiangsu Key Laboratory of Gastrointestinal Nutrition and \\ Animal Health, College of Animal Science and Technology, Nanjing Agricultural University, \\ Nanjing 210095, Jiangsu, China; zhengweijiang@njau.edu.cn (W.Z.); jixuchance@gmail.com (X.J.); \\ zhangqingzee@163.com (Q.Z.) \\ 2 Laboratory of Animal Reproduction, College of Animal Science and Technology, \\ Nanjing Agricultural University, Nanjing 210095, Jiangsu, China; wencdu@163.com (W.D.); \\ weiquanwei@njau.edu.cn (Q.W.) \\ 3 Key Lab of Animal Physiology and Biochemistry, Ministry of Agriculture, Nanjing 210095, Jiangsu, China \\ * Correspondence: yaowen67jp@njau.edu.cn; Tel.: +86-25-8439-9830
}

Received: 7 May 2018; Accepted: 30 May 2018; Published: 4 June 2018

\begin{abstract}
The objective of the current experiment was to evaluate whether hydrogen-rich water (HRW) or lactulose (LAC) could protect against the adverse effects of Fusarium mycotoxins-contaminated diet on the growth performance and antioxidant status in weaning piglets. A total of 24 individually housed female piglets were randomly assigned to receive four treatments for 25 days (six pigs/treatment): uncontaminated basal diet (negative control), mycotoxin-contaminated (MC) diet, MC diet + HRW (MC + HRW) and MC diet + LAC (MC + LAC). The plasma hydrogen levels before and after $2 \mathrm{~h}$ hydrogen-free water/HRW administration were detected at day 21 , and the liver hydrogen levels were detected at the end of the experiment. Serum hormones related to appetite regulation, and serum and liver oxidant and antioxidant status were also measured at the end of the experiment. Results showed that both HRW and LAC treatments significantly attenuated the reduction of average daily gain (ADG) and average daily feed intake (ADFI) caused by Fusarium mycotoxins. LAC administration increased the hydrogen concentrations in plasma and liver. HRW treated group had higher plasma hydrogen levels than the MC group. Compared with the NC group, the MC group had significantly increased serum peptide YY (PYY) and cholecystokinin (CCK) levels. Interestingly, both HRW and LAC administrations had a lower reduced serum PYY and CKK levels. Most importantly, oral administration of HRW and LAC attenuated the Fusarium mycotoxins-induced oxidative stress. In conclusion, oral administration of hydrogen-rich water or lactulose could both protect against the growth reduction and oxidative damage caused by Fusarium mycotoxins.
\end{abstract}

Keywords: lactulose; hydrogen-rich water; Fusarium mycotoxin; growth suppression; oxidative stress; piglet

Key Contribution: Our results showed that both hydrogen-rich water and lactulose treatments not only attenuated the reduction of average daily gain and average daily feed intake but also increased the serum concentration of appetite-regulating hormones in piglets fed Fusarium mycotoxins-contaminated corn. 


\section{Introduction}

Fusarium mycotoxins are secondary metabolites produced by Fusarium species of fungi, which can contaminate animal feed ingredients. Deoxynivalenol (DON) and zearalenone (ZEN) are considered to be the most important Fusarium mycotoxins due to their high toxicity [1]. A global survey indicated that Fusarium mycotoxins DON and ZEN, respectively, contaminated $55 \%$ and $36 \%$ of feed and feed ingredients in the period 2004-2011 [2], which results in a large economic loss in the livestock industry. Among farm animals, pigs are particularly sensitive to Fusarium mycotoxins [3]. Ingestion of DON is usually associated with feed refusal, low weight gains, low feed efficiency, diarrhea, and organ damage in pigs $[3,4]$. DON also significantly alters functions of the intestinal tract, including decreasing villus surface area and altering the permeability of the intestinal tract in weaning piglets [5]. Treatment with ZEN leads to hyperestrogenism, precocious puberty, and reproductive disorders [1,3]. In many cases, DON and ZEN often simultaneously found in naturally Fusarium fungi contaminated feed. Therefore, the co-occurrence of mycotoxins may make their toxicity effects on pigs more complicated. The liver is one of the main organs for metabolism of toxic substances, and liver damage might occur when pigs consume overdoses of mycotoxins [6]. An increasing number of studies have demonstrated that oxidative stress plays a major role in the toxicity of Fusarium mycotoxins $[7,8]$.

Hydrogen gas $\left(\mathrm{H}_{2}\right)$, historically thought an inert and nonfunctional gas, is defined as a selective antioxidant in recent years. Molecular hydrogen can selectively neutralize toxic free radicals such as hydroxyl radicals and nitrite anion without disturbing physiological reactive oxygen species (ROS) [9]. Unlike common antioxidant reagents, hydrogen has a unique advantage that it can penetrate biomembranes and diffuse into cellular components [10]. As a result, hydrogen has been applied in many animal liver damage models through its anti-inflammatory, anti-apoptotic, and anti-oxidant properties [11]. Inhalation of $\mathrm{H}_{2}$ gas suppresses hepatic ischemia/reperfusion injury by reducing oxidative stress in mice [12]. Hydrogen-rich water (HRW) has also shown remarkable protective effects against obstructive jaundice [13] and chronic EtOH-induced [14] liver damage, possibly by activating antioxidant enzymes.

Supplementation of hydrogen-producing prebiotics is also a feasible way of providing functional hydrogen to animals and humans [11]. Lactulose, a nonabsorbable synthetic disaccharide consisting of fructose and galactose, has been proposed as an indirect antioxidant by mobilizing intestinal hydrogen production [15]. Lactulose possesses neuroprotective [16] effects against cerebral ischemia/reperfusion injury and anti-inflammatory $[17,18]$ effects on dextran sodium sulfate-induced colon inflammatory, which could be ascribed to the hydrogen production produced during microbial fermentation of lactulose. Lactulose administration accelerates liver regeneration in a rat hepatectomy model by inducing hydrogen [19]. Previous strategies to mitigate the toxic effects of Fusarium mycotoxins in animal production involved mycotoxins adsorbent and mycotoxins-degrading enzymes and micro-organisms.

We hypothesize that both HRW and lactulose may protect weaning piglets against growth depression and liver damage caused by Fusarium mycotoxins contaminated diet by increasing hydrogen levels and activating the antioxidant capacity in the body.

\section{Results}

\subsection{Hydrogen Concentrations in Plasma and Liver}

On day 21 of the experiment, plasma samples were collected for measuring hydrogen levels before and two hours after different administrations in four groups (Figure 1). Before administration, MC + LAC group had higher plasma hydrogen concentrations than the other three groups $(p<0.05)$; and no difference was found among the NC, MC and MC + HRW groups $(p>0.05)$. After two hours of oral administration, the levels of hydrogen in the MC + HRW group were greater than in the NC, MC and MC + LAC groups $(p<0.05)$. In addition, the MC + LAC group also had higher plasma hydrogen levels than the MC and NC groups $(p<0.05)$. No difference was found in the plasma 
hydrogen levels between the NC and MC groups ( $p>0.05)$. At the end of the experiment (30 min after administration), hydrogen levels in the liver samples were further assayed (Figure 1). Results showed that liver hydrogen levels were not different among the NC, MC and MC + HRW groups $(p>0.05)$. However, the MC + LAC group had a higher hydrogen concentration in the liver than the other three groups $(p<0.05)$.

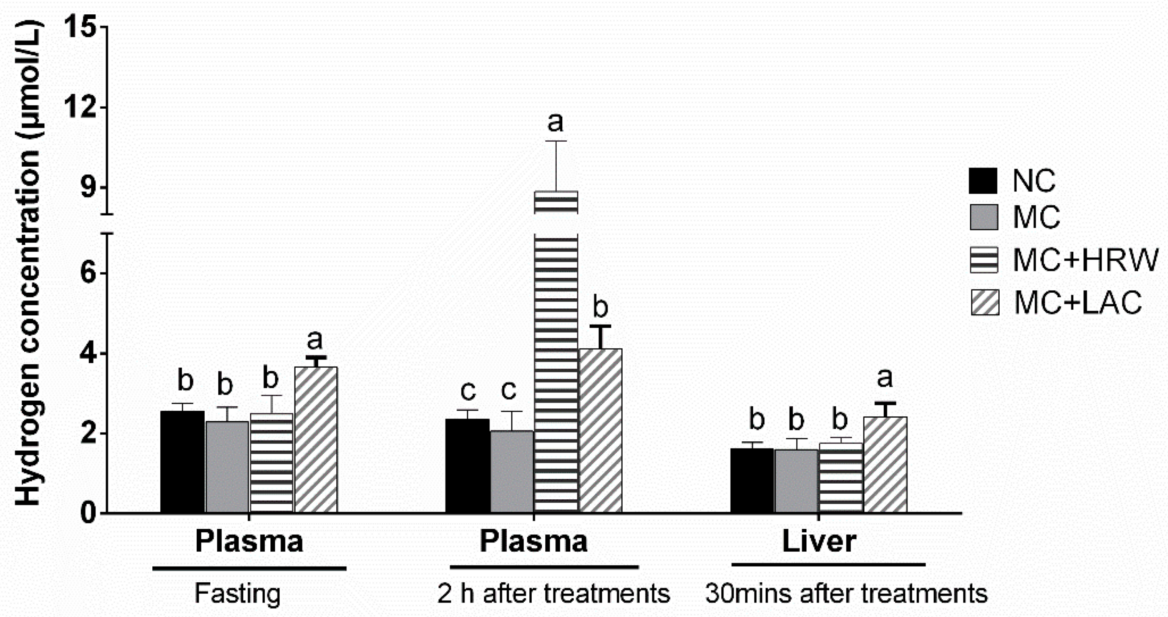

Figure 1. Effects of lactulose and hydrogen-rich water on plasma and liver hydrogen concentrations in female piglets fed Fusarium mycotoxins contaminated diets. Each column represents the mean hydrogen levels with five independent replicates, mean \pm SD. a-c Letters above the bars indicate statistical significance $(p<0.05)$ among the four treatments. NC (negative control), basal diet; MC, Fusarium mycotoxins contaminated diet; MC + LAC, MC diet + lactulose treatment; and MC + HRW, $\mathrm{MC}$ diet + hydrogen-rich water treatment.

\subsection{Growth Performance}

Body weight (BW), average daily weight gain (ADG), average daily feed intake (ADFI), and feed to gain ratio $(\mathrm{G}: \mathrm{F})$ from three different time periods are summarized in Table 1 . The BW on day 0 , day 14 and day 25 were not different among the four treatments $(p>0.05)$. However, the ADG from days 0 to 14 and days 0 to 25 periods were considerably decreased by mycotoxins contaminated diet $(p<0.05)$. Compared with the MC group, both HRW and LAC groups had increased the average daily gain (ADG) $(p<0.05)$. Fusarium mycotoxins drastically reduced the ADFI in three different time periods from days 0 to 14 , days 14 to 21 and days 0 to 25 ( $p<0.05)$. However, HRW and LAC treatments increased the ADFI during the periods of days 0 to 14 and days 0 to $25(p<0.05)$. The ratio of $\mathrm{G}: \mathrm{F}$ showed no difference among the treatments $(p>0.05)$.

Table 1. Effects of hydrogen-rich water and lactulose on growth performance in female piglets fed Fusarium mycotoxins contaminated diets ${ }^{1,2}$.

\begin{tabular}{ccccccc}
\hline Item & NC & MC & MC + LAC & MC + HRW & SEM & $p$-Value \\
\hline \multicolumn{7}{c}{ BW, kg } \\
\hline Day 0 & 7.66 & 7.88 & 7.76 & 8.00 & 0.20 & 0.947 \\
Day 14 & 12.42 & 10.42 & 12.27 & 12.14 & 0.39 & 0.244 \\
Day 25 & 18.78 & 14.44 & 17.70 & 17.48 & 0.61 & 0.056 \\
\hline \multicolumn{7}{c}{ ADG, kg/day } \\
\hline Days 0 to 14 & $0.34^{\text {a }}$ & $0.18^{\mathrm{b}}$ & $0.32^{\mathrm{a}}$ & $0.29^{\mathrm{a}}$ & 0.02 & 0.013 \\
Days 14 to 25 & 0.58 & 0.36 & 0.49 & 0.48 & 0.03 & 0.055 \\
\hline
\end{tabular}


Table 1. Cont.

\begin{tabular}{ccccccc}
\hline Item & NC & MC & MC + LAC & MC + HRW & SEM & $p$-Value \\
\hline Days 0 to 25 & $0.44^{\mathrm{a}}$ & $0.26^{\mathrm{b}}$ & $0.40^{\mathrm{a}}$ & $0.38^{\mathrm{a}}$ & 0.02 & 0.008 \\
\hline \multicolumn{7}{c}{ ADFI, g/day } \\
\hline Days 0 to 14 & $0.58^{\mathrm{a}}$ & $0.39^{\mathrm{b}}$ & $0.53^{\mathrm{a}}$ & $0.58^{\mathrm{a}}$ & 0.03 & 0.010 \\
Days 14 to 25 & $1.04^{\mathrm{a}}$ & $0.66^{\mathrm{b}}$ & $0.86^{\mathrm{a}, \mathrm{b}}$ & $0.87^{\mathrm{a}, \mathrm{b}}$ & 0.05 & 0.034 \\
Days 0 to 25 & $0.79^{\mathrm{a}}$ & $0.51^{\mathrm{b}}$ & $0.67^{\mathrm{a}}$ & $0.71^{\mathrm{a}}$ & 0.03 & 0.017 \\
\hline & & G:F, g/g & & \\
\hline Days 0 to 14 & 0.59 & 0.46 & 0.60 & 0.51 & 0.02 & 0.060 \\
Days 14 to 25 & 0.56 & 0.56 & 0.59 & 0.55 & 0.02 & 0.948 \\
Days 0 to 25 & 0.57 & 0.53 & 0.60 & 0.53 & 0.02 & 0.358 \\
\hline
\end{tabular}

a,b Values with different letters within the same row are different $(p<0.05) .{ }^{1} \mathrm{NC}$ (negative control), basal diet; MC, Fusarium mycotoxins contaminated diets; MC + LAC, MC diet + lactulose treatment; and MC + HRW, MC diet + hydrogen-rich water treatment. ${ }^{2} n=5$.

\subsection{Serum Levels of Appetite-Regulating Hormones}

Table 2 shows that no difference was found in the serum ghrelin concentration among the four groups $(p>0.05)$. However, Fusarium mycotoxins contaminated maize resulted in higher serum peptide YY (PYY) and cholecystokinin (CCK) concentrations compared with the negative control diet (Table 2). Both MC + LAC and MC + HRW groups had lower serum PYY and CKK levels than the MC group $(p<0.05)$, and no difference was found when they were compared with the NC group $(p>0.05)$.

Table 2. Effects of hydrogen-rich water and lactulose on serum hormones levels in female piglets fed Fusarium mycotoxins contaminated diets ${ }^{1,2}$.

\begin{tabular}{ccccccc}
\hline Item & NC & MC & MC + LAC & MC + HRW & SEM & $p$-Value \\
\hline Ghrelin (ng/L) & 3743.92 & 3064.05 & 3533.69 & 3587.87 & 85.79 & 0.112 \\
PYY (pg/mL) & $740.09^{\mathrm{b}}$ & $837.44^{\mathrm{a}}$ & $729.94^{\mathrm{b}}$ & $727.60^{\mathrm{b}}$ & 13.77 & 0.003 \\
CCK (ng/L) & $178.29^{\mathrm{b}}$ & $211.72^{\mathrm{a}}$ & $176.26^{\mathrm{b}}$ & $157.63^{\mathrm{b}}$ & 7.65 & 0.007 \\
\hline
\end{tabular}

a,b Values with different letters within the same row are different $(p<0.05) .{ }^{1} \mathrm{NC}$ (negative control), basal diet; MC, Fusarium mycotoxins contaminated diets; MC + LAC, MC diet + lactulose treatment; and MC + HRW, MC diet + hydrogen-rich water treatment. ${ }^{2} n=5$.

\subsection{Oxidative and Antioxidative Status in the Serum and Liver}

\subsubsection{Serum Oxidant Markers and Antioxidant Capacity}

Indicators of serum oxidative and antioxidant status are presented in Table 3. The activities of serum catalase (CAT), total superoxide dismutase (SOD), CuZn-SOD, and Mn-SOD were not different among the NC, MC, MC + LAC and MC + HRW groups $(p>0.05)$. The serum total carbonyl and 8-hydroxydeoxyguanosine (8-OH-dG) levels in the MC group were significantly higher than in the other three groups $(p<0.05)$, whereas no difference was found among the NC, MC + LAC and MC + HRW groups $(p>0.05)$. Serum malondialdehyde (MDA) levels in the MC + LAC group were lower than the MC group $(p<0.05)$, while no difference was found among the $\mathrm{NC}, \mathrm{MC}$ and MC + HRW groups $(p>0.05)$. 
Table 3. Effects of hydrogen-rich water and lactulose on blood antioxidant capacity in female piglets fed Fusarium mycotoxins contaminated diets ${ }^{1,2}$.

\begin{tabular}{ccccccc}
\hline Items & NC & MC & MC + LAC & MC + HRW & SEM & $p$-Value \\
\hline Total carbonyl $(\mathrm{mg} / \mathrm{mL})$ & $0.78^{\mathrm{b}}$ & $1.07^{\mathrm{a}}$ & $0.84^{\mathrm{b}}$ & $0.86^{\mathrm{b}}$ & 0.04 & 0.047 \\
8-OH-dG $(\mathrm{ng} / \mathrm{mL})$ & $8.41^{\mathrm{b}}$ & $11.97^{\mathrm{a}}$ & $8.24^{\mathrm{b}}$ & $8.14^{\mathrm{b}}$ & 0.48 & 0.002 \\
MDA $(\mathrm{nmol} / \mathrm{mL})$ & $4.15^{\mathrm{a}, \mathrm{b}}$ & $4.79^{\mathrm{a}}$ & $3.23^{\mathrm{b}}$ & $3.66^{\mathrm{a}, \mathrm{b}}$ & 0.29 & 0.043 \\
CAT $(\mathrm{U} / \mathrm{mL})$ & 2.54 & 3.96 & 2.52 & 2.86 & 0.23 & 0.079 \\
Total-SOD $(\mathrm{U} / \mathrm{mL})$ & 76.06 & 77.43 & 77.02 & 73.69 & 1.11 & 0.669 \\
CuZn-SOD $(\mathrm{U} / \mathrm{mL})$ & 72.20 & 70.94 & 74.16 & 69.33 & 1.20 & 0.576 \\
Mn-SOD $(\mathrm{U} / \mathrm{mL})$ & 6.06 & 6.48 & 5.86 & 6.56 & 0.19 & 0.562 \\
\hline a,b Values with different letters within the same row are different $(p<0.05) .{ }^{1}$ NC (negative control), basal diet; MC, \\
Fusarium mycotoxins contaminated diets; MC + LAC, MC diet + lactulose treatment; and MC + HRW, MC diet + \\
hydrogen water treatment. ${ }^{2} n=5$.
\end{tabular}

\subsubsection{Liver Oxidant and Antioxidant Capacity}

Table 4 shows the liver oxidative and antioxidant status. Protein carbonyl, MDA, glutathione peroxidase (GSH-px), glutathione (GSH), GSSG, and reduced GSH levels were not different among the $\mathrm{NC}, \mathrm{MC}, \mathrm{MC}+\mathrm{LAC}$ and MC + HRW groups $(p>0.05)$. The total carbonyl levels in the MC group were higher $(p<0.05)$ than in the MC + LAC and MC + HRW groups, whereas no difference was found between the NC and MC groups $(p>0.05)$. The inhibiting hydroxyl radical levels were not affected by Fusarium mycotoxins $(p>0.05)$, while the MC + HRW group had a higher inhibiting hydroxyl radical levels than the MC + LAC and NC groups $(p<0.05)$. The CAT levels in the MC + LAC and MC + HRW groups were lower than the MC group $(p<0.05)$, but no difference was found between the NC and MC groups $(p>0.05)$.

Table 4. Effects of hydrogen-rich water and lactulose on the liver antioxidant status in female piglets fed Fusarium mycotoxins contaminated diets ${ }^{1,2}$.

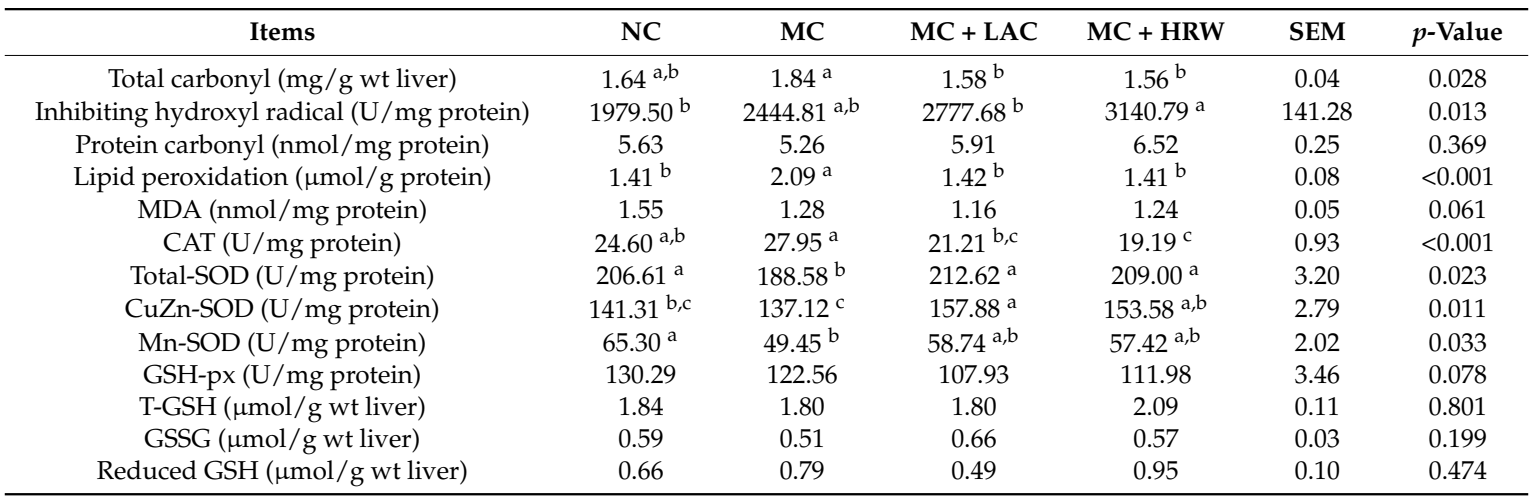

${ }^{\mathrm{a}-\mathrm{c}}$ Values with different letters within the same row are different $(p<0.05) .{ }^{1} \mathrm{NC}$ (negative control), basal diet; MC, Fusarium mycotoxins contaminated diets; MC + LAC, MC diet + lactulose treatment; and MC + HRW, MC diet + hydrogen water treatment. ${ }^{2} n=5$.

Total SOD, CuZn-SOD, and Mn-SOD were significantly impacted by the treatments. The total SOD activity in the MC group was significantly lower than in the NC, MC + LAC and MC + HRW groups $(p<0.05)$, and no difference was found among the NC, MC + LAC and MC + HRW groups $(p>0.05)$. The CuZn-SOD activity in the MC + LAC and MC + HRW was significantly higher than in the MC group $(p<0.05)$, and no difference was found between the NC and MC groups $(p>0.05)$. The Mn-SOD enzyme activity in the MC group was also significantly lower $(p<0.05)$ than in the NC group, and no difference was found between the MC + LAC and MC + HRW groups $(p>0.05)$. 


\section{Discussion}

In the present study, we tested the hypothesis that administration of hydrogen-rich water or lactulose might protect against the adverse effects of Fusarium mycotoxins contaminated diet on growth performance and antioxidant status in female weaning piglets.

\subsection{Hydrogen Concentration in Serum and Liver}

Based on previous studies [20,21], we orally administrated hydrogen-rich water $(10 \mathrm{~mL} / \mathrm{kg} \mathrm{BW}$, $0.6 \mathrm{mM}$ ) and $500 \mathrm{mg} / \mathrm{kg}$ BW lactulose (two times/day) to piglets fed mycotoxins contaminated diet, respectively. To date, many researchers have reported the hydrogen concentrations in blood and tissues in vivo following administration of exogenous hydrogen treatment [22-24] or lactulose [16,19] using rodent models. However, the effects of hydrogen-rich water and lactulose on blood and liver hydrogen status in female piglets have never been addressed. A previous study showed that hydrogen concentrations reached the peak levels at $5 \mathrm{~min}$ after oral and intraperitoneal (IP) administration in rats [22], and highest hydrogen concentrations in the blood and tissues were observed at $30 \mathrm{~min}$ after the inhalation of hydrogen gas. Furthermore, breath $\mathrm{H}_{2}$ content rapidly reached to its maximal level $10 \mathrm{~min}$ after ingestion, and decreased to the baseline level within $60 \mathrm{~min}$ in adult volunteers [25]. Molecular hydrogen is produced continuously under normal physiological condition, primarily during the fermentation of nondigestible carbohydrates by bacteria in the large intestine. Recent evidence indicated that inhalation of hydrogen gas or HRW/hydrogen-rich saline or lactulose treatment could significantly increase the hydrogen concentrations in blood and tissues [22]. Here, plasma samples before and two hours after different oral treatments in piglets were collected. In addition, liver tissue was sampled after $30 \mathrm{~min}$ of administrations. Our data showed that Fusarium mycotoxins did not affect the hydrogen status in the plasma and liver (Figure 1). Considering the features of LAC and HRW, it is expected that lactulose administration caused a constant increase in plasma and liver concentrations of hydrogen (Figure 1), while HRW treatment only caused an increment in plasma samples after $2 \mathrm{~h}$ of administration.

Due to the high diffusion capability of $\mathrm{H}_{2}$, drinking hydrogen-rich water rapidly increased breath and tissues hydrogen content [22-25]. On the other hand, bacteria fermentation of lactulose will lead to a continual gas production, including hydrogen gas. Therefore, the difference of the hydrogen lease rate between the hydrogen-rich water and lactulose might contribute the discordance hydrogen concentrations between plasma and liver in the current study. Although higher hydrogen levels were observed in the LAC (plasma and liver) and HRW (plasma) treatments compared with the MC group, they do not represent the whole $\mathrm{H}_{2}$ production of HRW or LAC, and the dynamics of hydrogen gas after administration of lactulose or hydrogen-rich water in the blood and tissues in piglets is still unknown. Further studies are required to accurately determine the hydrogen concentrations in various tissues of piglets, which are very important for the application of hydrogen gas in animal production.

\subsection{Growth Performance}

Due to the dysfunctions of immune and digestive systems, weaning piglets is especially vulnerable to toxic substances, which may reduce growth performance and impair health condition. In a previous study, Fusarium mycotoxins contaminate maize $(8.6 \mathrm{mg} / \mathrm{kg}$ DON and $1.2 \mathrm{mg} / \mathrm{kg}$ ZEN) was incorporated into a maize-based diet for piglets at $50 \%$ at the expense of control maize (equal to $4.3 \mathrm{mg} / \mathrm{kg}$ DON and $600 \mu \mathrm{g} / \mathrm{kg}$ ZEN). After five weeks of feeding, voluntary feed intake, and body weight gain were significantly decreased while the feed conversion ratio was not affected [26]. Cheng et al. [27] reported that feeding DON and ZEN contaminated diet $(1.0 \mathrm{mg} / \mathrm{kg}$ DON and $250 \mu \mathrm{g} / \mathrm{kg}$ ZEN) significantly reduced the body weight, daily feed intake and ADG in weaning piglets. In our experiment, a similar result has been observed. In addition, symptoms include diarrhea, fever and refusal to feed were observed in piglets fed Fusarium mycotoxins contaminated maize. In this study, piglets were fed with relatively low Fusarium mycotoxins levels (501.56 $\mu \mathrm{g} / \mathrm{kg}$ ZEN, $825.46 \mu \mathrm{g} / \mathrm{kg}$ DON and $272.54 \mu \mathrm{g} / \mathrm{kg}$ DON acetylated derivatives). It should be pointed out that the co-occurrence of mycotoxins in naturally Fusarium fungi contaminated 
feed may cause more intense toxicity [8]. It needs to be mentioned that the interactions between DON and ZEN may not be precisely predicted, since the possible presence of unknown Fusarium toxins may possess similar or even different modes of action, even if similar concentrations are applied [26].

Prebiotics are defined as "selectively fermented ingredients that result in specific changes in the composition and/or activity of the gastrointestinal microbiota, thus conferring benefits upon host health" [28]. In pigs, lactulose has been used as a prebiotic with beneficial effects cited as stimulating the growth of health-promoting bacteria in the gut and promoting growth performance $[29,30]$. Krueger et al. [31] reported that lactulose supplementation in periparturient sows reduced the length of pregnancy, and losses of their piglets and weaners, and increased daily weight gains and weight of weaners. A previous study also reported that $1 \%$ lactulose dietary supplementation in weaning piglets for two weeks enhanced feed intake, average daily gain and feed: gain ratio, which might be related to increased feed intake and improved gut integrity [29]. Furthermore, dietary lactulose addition $(10 \mathrm{~g} / \mathrm{kg})$ was reported to increase the average daily weight gain after an oral enterotoxigenic E. coli K88 challenge in weaning piglets [21]. Here, our data showed that $500 \mathrm{mg} / \mathrm{kg}$ BW lactulose administration (two times/day) significantly attenuated the reduction of ADG and ADFI caused by Fusarium mycotoxins in weaning piglets. The ability to selectively change the composition of intestinal microbiota and/or intestinal integrity might be the underlying mechanisms of lactulose's growth-promoting effects against Fusarium mycotoxins. However, recent evidence indicated that hydrogen gas may play a non-negligible role in lactulose's beneficial effects [16-19]. In the present study, $10 \mathrm{~mL} / \mathrm{kg}$ BW of HRW (two times/day) to weaning piglets was found to significantly enhance the ADG and ADGI in piglets fed Fusarium mycotoxins contaminated diet. To our knowledge, this is the first evidence that hydrogen-rich water could spare the harmful effect of Fusarium mycotoxins on growth performance of weaning piglets.

\subsection{Serum Gut Appetite-Regulating Hormones Levels}

Satiety hormones play a role in mediating Fusarium toxins-induced anorexia [4,32]. Gut satiety hormones peptide YY (PYY) and cholecystokinin (CCK) contributed to the feed refusal [33,34]. Feed refusal and higher plasma PYY and CCK levels were found in mice treated with DON, and direct administration of exogenous PYY or CCK also caused reduced food intake in mice [35]. In the current experiment, Fusarium mycotoxins increased the serum PYY and CCK levels compared with the NC group in weaning piglets. These findings are consistent with those studies which reported that both oral and IP administrations of DON in mice increased plasma CCK and PYY levels with concurrent food refusal [35,36]. Here, serum PYY and CKK levels were attenuated by both HRW and LAC administrations (Table 3). Ghrelin has been demonstrated to increase food intake, and promote weight gain and adiposity in rodents [37]. Although no difference was found in serum ghrelin levels in this study, a recent study demonstrated that orally administered hydrogen-rich water significantly increased gastric production of the ghrelin in mice [38]. This might suggest that satiety hormones are important for mediating the effects of lactulose and HRW on food intake and growth performance. Further studies are required to determine the possible underlying mechanisms.

\subsection{Oxidative Stress}

Studies have shown that oxidative stress plays an important role in the cytotoxic mechanism of mycotoxins $[7,8]$. The adverse effects of Fusarium mycotoxins on serum and hepatic oxidative stress vary with among studies, animal species, mycotoxins composition, and exposure time. For example, male broiler chickens exposed to $10 \mathrm{mg} / \mathrm{kg}$ DON for 17 days did not alter the total antioxidant status in plasma and glutathione peroxidase (GPx) levels in the liver [39]. No significant difference was found in serum total antioxidant status and GPx activity in male pigs after 14 days DON (4 mg/kg feeds) treatment [40]. However, higher plasma $\mathrm{H}_{2} \mathrm{O}_{2}$ and MDA levels were found in piglets fed the DON-contamination diet at $4 \mathrm{mg} / \mathrm{kg}$ for 30 days [41]. The high amount of ZEN in the contaminated diet may also contribute to oxidative stress in the liver or serum because purified ZEN can increase the MDA level in the serum and liver in piglets [42]. In addition, prepubertal gilts fed with diets contaminated with ZEN (0.5 and 
$2 \mathrm{mg} / \mathrm{kg}$ ) had lower MDA, GPx, and SOD in the serum [43]. Combined with the serum biochemical variables (data not published), it is reasonable that piglets fed the MC diet had higher oxidative stress biomarkers (total carbonyl, lipid peroxidation, CAT, and 8-OH-dG) and lower antioxidant enzymes (total $\mathrm{SOD}, \mathrm{CuZn}-\mathrm{SOD}$, and Mn-SOD) in the serum and hepatic samples.

Many studies have reported that the hydrogen gas exerts organ-protective effects through regulating oxidative stress, inflammation, and apoptosis [9]. Li et al. [44] observed that hydrogen saline treatment decreased oxidative neuronal stress by reducing MDA levels in the brains of Alzheimer rats. The same team also found that hydrogen-rich saline treatment decreased the levels of IL- $1 \beta, 8-\mathrm{OH}-\mathrm{dG}$, JNK, and $\mathrm{NF}-\mathrm{kB}$ in the amyloid-beta induced neural inflammation and oxidative rat model [45]. Lactulose, as a special class of carbohydrate, showed the protective effect on several animal models of injuries caused by oxidative stress through hydrogen gas production [16-18]. In this study, both lactulose and HRW treatments not only ameliorated the reduction of growth performance but also reduced the oxidative biomarkers levels in the serum and liver. Moreover, the activities of the CAT, total SOD, CuZn-SOD, and Mn-SOD levels were also improved in hepatic samples, demonstrating that the beneficial effects of lactulose and HRW on growth performance were partially mediated through their antioxidative property. The possible scientific explanations for the biological activities of lactulose in this study might be summarized as follows: (a) prebiotics compounds can decrease the bioaccessibility of mycotoxins, with a concentration-dependent behavior [46]; (b) the synthetic disaccharide lactulose acts as a prebiotic that enhanced growth performance of piglets [21]; and (c) dramatic endogenous biological molecule hydrogens can be produced by bacteria fermentation [47]. The similar protective effects between lactulose and HRW also may partially support our hypothesis that hydrogen gas was one factor contributing to the LAC's biological activities in countering the mycotoxins side effects. This study provides data that might help to propose a novel explanation that endogenous hydrogen gas might contribute to the beneficial effect of prebiotics. Therefore, dietary supplementation of lactulose or drinking HRW might be used as a novel antioxidant against Fusarium mycotoxins-induced mycotoxicosis in swine production. However, it must be kept in mind that this study was performed in a controlled environment with a limited number of pigs. Further studies are warranted to analyze the therapeutic effects of HRW and lactulose for piglets fed with mycotoxins contaminated diets.

\section{Conclusions}

The present results indicated that consumption of Fusarium mycotoxin-contaminated diets led to growth depression, organ damage, and oxidative stress in female piglets. Hydrogen-rich water and lactulose protected against the Fusarium mycotoxins induced growth depression and oxidative stress. These findings partly support our original hypothesis that supplementation of hydrogen-producing prebiotic may improve the antioxidant capacity by increasing intestinal hydrogen production in female weaning piglets.

\section{Materials and Methods}

\subsection{Preparation of Fusarium Contaminated Maize}

Fusarium graminearum strain 2021 was kindly supplied by Prof. Ming-Guo Zhou, College of Plant Protection, Nanjing Agricultural University, Nanjing, China. The strain was cultured as described in a previous study [48]. Briefly, the strain was first cultivated on potato sucrose agar (PSA) at $25^{\circ} \mathrm{C}$ for 7 days. The hyphae of fungi were obtained, inoculated in mung bean broth (MBB), and cultured with shaking $\left(200 \mathrm{rpm} / \mathrm{min}\right.$ at $25^{\circ} \mathrm{C}$ ) for 7 days for conidia production. Before inoculation, maize was soaked with water for $48 \mathrm{~h}$ and autoclaved. The conidia were inoculated to cool autoclaved maize at a concentration of $1 \times 10^{6}$ conidia $/ \mathrm{kg}$. The Fusarium contaminated maize was incubated in plastic storage boxes for 30 days (temperature $15-25{ }^{\circ} \mathrm{C}$ and humidity $50-85 \%$ ). The cool autoclaved maize not inoculated with conidia was used as control maize. Finally, control and maize with Fusarium mold were dried in an oven at $70{ }^{\circ} \mathrm{C}$ for $24 \mathrm{~h}$, respectively. 


\subsection{Experimental Diets and Mycotoxins Analysis}

Fusarium mycotoxins-contaminated maize and uncontaminated control maize were used at $50 \%$ at the expense of normal maize for the manufacturing of two experimental diets, respectively. The experimental diets were formulated according to the recommendations of the nutrient requirement of swine by National Research Council [49] and based on a previous study [41], with a minor modification to the vitamin and mineral premix. No antibiotic, hormone and preservatives were added to the diets. Table A1 shows the ingredients of the experimental diets used in this study.

Fusarium mycotoxins levels in the two experimental diets were analyzed as previously described [50]. Briefly, a $10 \mathrm{~g}$ diet sample was extracted with $25 \mathrm{~mL}$ of acetonitrile:water $(80: 20, v / v)$ at $180 \mathrm{rpm}$ for $30 \mathrm{~min}$. After centrifugation at $3000 \mathrm{rpm}$ for $10 \mathrm{~min}, 0.5 \mathrm{~mL}$ supernatant was diluted with $1.5 \mathrm{~mL}$ of acetonitrile:water $(80: 20, v / v)$ and filtered through a nylon filter $(13 \mathrm{~mm}$ in diameter and $0.22 \mu \mathrm{m}$ pore size). Then, the filtered solution was analyzed by a high-pressure liquid chromatography/electrospray ionization-tandem mass spectrometry (LC-MS/MS) system consisting of an Agilent 1200 HPLC (Agilent Technology, Shanghai, China), an Agilent 6410B triple-quadrupole mass spectrometer (Agilent Technology, Shanghai, China), and an Agilent MassHunter Workstation running Qualitative Analysis version B.01.03 software (Agilent Technology, Shanghai, China, 2001) for data acquisition and analysis. No significant differences were found in nutrient composition between the NC and MC experimental diets (Table A1). Levels of the main Fusarium mycotoxins in 2 experimental diets are summarized in Table A2. The NC diet contained $221.10 \mu \mathrm{g} / \mathrm{kg}$ DON, $12.12 \mu \mathrm{g} / \mathrm{kg}$ 3-acetyl DON, $32.95 \mu \mathrm{g} / \mathrm{kg}$ 15-acetyl DON, and $266.26 \mu \mathrm{g} / \mathrm{kg}$ total DON, respectively. While the MC diet contained $825.46 \mu \mathrm{g} / \mathrm{kg}$ DON, $212.79 \mu \mathrm{g} / \mathrm{kg}$ 3-acetyl DON, $59.45 \mu \mathrm{g} / \mathrm{kg}$ 15-acetyl DON, $1097.99 \mu \mathrm{g} / \mathrm{kg}$ total DON, and $501.56 \mu \mathrm{g} / \mathrm{kg}$ ZEN, which were all significantly higher $(p<0.05)$ than in the NC $\operatorname{diet}($ Table A2).

\subsection{Animals}

All experiments and protocols used in this study were approved by the Nanjing Agricultural University Institutional Animal Care and Use Committee (Certification No.: SYXK (Su) 2011-0036, 11 August 2015). A total of 24 clinically healthy female weaning piglets (Landrace $\times$ large $\times$ white) from 6 littles (4 pigs/little) were individually housed in pens ( 1.2 by $2.0 \mathrm{~m}$ ) with 1 feeder and 1 nipple drinker. The piglets had ab libitum access to feed and water.

\subsection{Experiment Design and Sample Collection}

The piglets from the same little were randomly assigned to receive 1 of 4 treatments (total 6 pigs/treatment): uncontaminated basal diet (negative control (NC)), mycotoxin-contaminated (MC) diet, MC diet + lactulose (MC + LAC) and MC diet + hydrogen-rich water (MC + HRW). After a 6-day adaption period, each treatment fed their respective diet for 25 days. Piglets received two times/day (10:00 and 14:00, respectively) and $10 \mathrm{~mL} / \mathrm{kg} \mathrm{BW} /$ time for their respective treatments. Piglets in NC and MC groups were orally administrated with hydrogen-free water (HFW), MC + HRW group received hydrogen-rich water (HRW), and MC + LAC group received $500 \mathrm{mg} / \mathrm{kg} \mathrm{BW}$ of LAC (dissolved in $10 \mathrm{~mL}$ of HFW). The hydrogen-rich water (Beijing Hydrovita Biotechnology Company, Beijing, China) was kept in $300 \mathrm{~mL}$ aluminum pouches and administered to piglets within 15 min after opened. The $\mathrm{H}_{2}$ concentration was $0.6 \mathrm{mM}$ as measured by an $\mathrm{H}_{2}$ sensor (Unisense, Aarhus, Denmark). Each animal's daily feed intake and weekly body weight were recorded. Amounts of HFW, LAC and HRW were dependent on the body weight and updated weekly.

On Day 21, plasma samples at fasting and two hours after different administrations were collected to detect the hydrogen levels. One piglet was removed from the MC, MC + LAC and MC + HRW groups fed with Fusarium mycotoxins contaminated maize due to the poor health condition. Therefore, five independent replicates from each group were used in this study. At the end of the experiment, $30 \mathrm{~min}$ after administration of different treatments, piglets were euthanized by an intramuscular injection of sodium pentobarbital ( $40 \mathrm{mg} / \mathrm{kg} \mathrm{BW})$. The serum and liver were sampled. 


\subsection{Serum Hormones and Antioxidant Assay}

Serum hormone levels of ghrelin, PYY, and CKK were measured by commercial ELISA kit according to their instructions (Fangcheng Beijing Technology Co. Ltd., Beijing, China). Liver samples were homogenized as previously described [51]. Oxidant and antioxidant parameters in the serum and liver supernatants were analyzed using assay kit according to the manufacturer's instructions (Nanjing Jiancheng, Nanjing, China).

\subsection{Hydrogen Gas Measurement in Plasma and Liver Samples}

Hydrogen levels in serum samples were analyzed using a hydrogen sensor (Unisense, Aarhus, Denmark). Samples of liver were prepared as previously described [52]. Briefly, piglets were euthanized with sodium pentobarbital and placed in supine position. An incision was made in the abdomen. Hydrogen microelectrode (diameter, $50 \mu \mathrm{m}$ ) was inserted into the liver at a depth of $500 \mu \mathrm{m}$.

\subsection{Statistical Analysis}

All statistical analyses were performed using the SPSS software (Version 18.0, SPSS Inc., Chicago, IL, USA, 2009). The differences among treatments were evaluated using one-way ANOVA followed by Tukey-Kramer test. Data were considered to be statistically significant if $p<0.05$.

Author Contributions: W.Z. and W.Y. have contributed to the conception and the design of the study; X.J., Q.Z. and W.D. carried out the experiments; X.J. and Q.Z. analyzed the data; W.Z., Q.W. and W.Y. contributed the reagents/materials/analysis tools; W.Z. drafted the manuscript; W.Y. revised the article. All authors read and approved final manuscript.

Acknowledgments: This work was supported by grants from the National Nature Science Foundation of China (31501986) and Fundamental Research Funds for Central Universities (KJQN201611). The authors would like to thank Ming-Guo Zhou and Ya-bing Duan for proving Fusarium graminearum strain 2021 and preparing the conidia. We thank Jin Cui for her kindly aid with hydrogen measurements in samples from piglets.

Conflicts of Interest: The authors declare no conflict of interest.

\section{Appendix A}

Table A1. Ingredient composition and nutrient contents of control and experimental diets.

\begin{tabular}{|c|c|c|}
\hline Item & $\mathrm{NC}^{1}$ Diet & MC $^{2}$ Diet \\
\hline \multicolumn{3}{|c|}{ Ingredients, \% } \\
\hline Normal corn & 16.75 & 16.75 \\
\hline Fusarium toxins uncontaminated corn & 44.50 & - \\
\hline Fusarium toxins contaminated corn & - & 44.50 \\
\hline Soybean meal & 15.79 & 15.79 \\
\hline Extruded soybean & 10.0 & 10.0 \\
\hline Fish meal & 5.0 & 5.0 \\
\hline Wheat bran & 3.0 & 3.0 \\
\hline Soybean oil & 1.74 & 1.74 \\
\hline Vitamin and mineral premix ${ }^{3}$ & 1.0 & 1.0 \\
\hline Limestone powder & 0.98 & 0.98 \\
\hline Calcium hydrogen phosphate & 0.78 & 0.78 \\
\hline Salt & 0.37 & 0.37 \\
\hline Lysine $\mathrm{HCl}(98 \%)$ & 0.09 & 0.09 \\
\hline Total & 100.00 & 100.00 \\
\hline \multicolumn{3}{|c|}{ Analyzed chemical composition ${ }^{4}$} \\
\hline $\mathrm{DM}, \%$ & 88.96 & 88.28 \\
\hline $\mathrm{CP}, \%$ & 20.11 & 20.4 \\
\hline Crude ash, \% & 4.70 & 4.89 \\
\hline Crude fiber, \% & 1.71 & 1.96 \\
\hline Ether extract, \% & 8.04 & 8.65 \\
\hline Calculated DE, ${ }^{5} \mathrm{kcal} / \mathrm{kg}$ & 3400.00 & 3400.00 \\
\hline
\end{tabular}

${ }^{1} \mathrm{NC}$, negative control (basal diet). ${ }^{2} \mathrm{MC}$, mycotoxin-contaminated diet. ${ }^{3}$ Provided, per kilogram of diet (as-fed basis) $55 \mathrm{mg} \mathrm{Zn}\left(\mathrm{ZnSO}_{4}\right), 30 \mathrm{mg} \mathrm{Cu}\left(\mathrm{CuSO}_{4}\right), 60 \mathrm{mg} \mathrm{Mn}\left(\mathrm{MnSO}_{4}\right), 120 \mathrm{mg}$ Fe $\left(\mathrm{FeSO}_{4}\right), 1 \mathrm{mg} \mathrm{I}(\mathrm{KI}), 2 \mathrm{mg} \mathrm{Co}\left(\mathrm{CoSO}_{4}\right)$, $0.3 \mathrm{mg}$ Se $\left(\mathrm{Na}_{2} \mathrm{SeO}_{3}\right), 9000 \mathrm{IU}$ vitamin $\mathrm{A}, 1800 \mathrm{IU}$ vitamin $\mathrm{D}_{3}, 40 \mathrm{IU}$ vitamin $\mathrm{E}, 3 \mathrm{mg}$ vitamin $\mathrm{B}_{1}, 4.5 \mathrm{mg}$ vitamin $\mathrm{B}_{2}, 16 \mathrm{mg}$ pantothenic acid, $10 \mathrm{mg}$ vitamin $\mathrm{B}_{6}, 0.08 \mathrm{mg}$ vitamin $\mathrm{B}_{12}, 28 \mathrm{mg}$ niacin, $2 \mathrm{mg}$ folic acid, $1.8 \mathrm{mg}$ vitamin $\mathrm{K}_{3}, 0.2 \mathrm{mg}$ biotin, $800 \mathrm{mg}$ choline chloride, and $100 \mathrm{mg}$ vitamin $\mathrm{C}$. The premix did not contain additional $\mathrm{Cu}, \mathrm{Zn}$, antibiotics, or probiotics. ${ }^{4}$ Unless indicated otherwise. ${ }^{5}$ Based on a DM content of $88 \%$. 
Table A2. Mycotoxins composition of basal and fusarium mycotoxins contaminated diet ${ }^{1,2}$.

\begin{tabular}{ccccc}
\hline Mycotoxin $(\mu \mathrm{g} / \mathrm{kg})$ & NC & MC & SEM & $p$-Value \\
\hline Deoxynivalenol (DON) & 221.10 & $825.46^{*}$ & 84.34 & $<0.01$ \\
3-acetyl DON & 12.12 & $212.79^{*}$ & 30.46 & $<0.01$ \\
15-acetyl DON & 32.95 & $59.75^{*}$ & 4.14 & $<0.01$ \\
Total DON & 266.16 & $1097.99^{*}$ & 116.30 & $<0.01$ \\
Zearalenone (ZEN) & 9.61 & $501.56^{*}$ & 69.82 & $<0.01$ \\
Nivalenol (NIV) & N.D & N.D & - & - \\
T-2 & N.D & N.D & - & - \\
\hline
\end{tabular}

${ }^{1} \mathrm{NC}$ (negative control), basal diet; MC, mycotoxin-contaminated diet; Limit of detections: DON, 3 -acrtyl and 15 -acetyl DON are $20 \mathrm{ng} / \mathrm{mL}$. ZEN, NIV and T-2 are $10 \mathrm{ng} / \mathrm{mL}$. N.D, not detected; ${ }^{2} n=3$. ${ }^{*}$ Value between the NC and MC groups are different $(p<0.05)$.

\section{References}

1. Cortinovis, C.; Pizzo, F.; Spicer, L.J.; Caloni, F. Fusarium mycotoxins: Effects on reproductive function in domestic animals-A review. Theriogenology 2013, 80, 557-564. [CrossRef] [PubMed]

2. Streit, E.; Naehrer, K.; Rodriguess, I.; Schatzmayr, G. Mycotoxin occurrence in feed and feed raw materials worldwide: Long-term analysis with special focus on Europe and Asia. J. Sci. Food Agric. 2013, 93, 2892-2899. [CrossRef] [PubMed]

3. Doll, S.; Danicke, S. The fusarium toxins deoxynivalenol (don) and zearalenone (zon) in animal feeding. Prev. Vet. Med. 2011, 102, 132-145. [CrossRef] [PubMed]

4. Escrivá, L.; Font, G.; Manyes, L. In vivo toxicity studies of fusarium mycotoxins in the last decade: A review. Food Chem. Toxicol. 2015, 78, 185-206. [CrossRef] [PubMed]

5. Xiao, H.; Tan, B.E.; Wu, M.M.; Yin, Y.L.; Li, T.J.; Yuan, D.X.; Li, L. Effects of composite antimicrobial peptides in weanling piglets challenged with deoxynivalenol: II. Intestinal morphology and function. J. Anim. Sci. 2013, 91, 4750-4756. [CrossRef] [PubMed]

6. Tiemann, U.; Danicke, S. In vivo and in vitro effects of the mycotoxins zearalenone and deoxynivalenol on different non-reproductive and reproductive organs in female pigs: A review. Food Addit. Contam. 2007, 24, 306-314. [CrossRef] [PubMed]

7. Doi, K.; Uetsuka, K. Mechanisms of mycotoxin-induced neurotoxicity through oxidative stress-associated pathways. Int. J. Mol. Sci. 2011, 12, 5213-5237. [CrossRef] [PubMed]

8. Hou, Y.-J.; Zhao, Y.-Y.; Xiong, B.; Cui, X.-S.; Kim, N.-H.; Xu, Y.-X.; Sun, S.-C. Mycotoxin-containing diet causes oxidative stress in the mouse. PLoS ONE 2013, 8, e60374. [CrossRef] [PubMed]

9. Ohta, S. Molecular hydrogen as a novel antioxidant: Overview of the advantages of hydrogen for medical applications. Methods Enzymol. 2015, 555, 289-317. [CrossRef] [PubMed]

10. Ohta, S. Molecular hydrogen is a novel antioxidant to efficiently reduce oxidative stress with potential for the improvement of mitochondrial diseases. Biochim. Biophys. Acta 2012, 1820, 586-594. [CrossRef] [PubMed]

11. Ge, L.; Yang, M.; Yang, N.N.; Yin, X.X.; Song, W.G. Molecular hydrogen: A preventive and therapeutic medical gas for various diseases. Oncotarget 2017, 8, 102653-102673. [CrossRef] [PubMed]

12. Fukuda, K.-I.; Asoh, S.; Ishikawa, M.; Yamamoto, Y.; Ohsawa, I.; Ohta, S. Inhalation of hydrogen gas suppresses hepatic injury caused by ischemia/reperfusion through reducing oxidative stress. BBRC 2007, 361, 670-674. [CrossRef] [PubMed]

13. Liu, Q.; Shen, W.F.; Sun, H.Y.; Fan, D.F.; Nakao, A.; Cai, J.M.; Yan, G.; Zhou, W.P.; Shen, R.X.; Yang, J.M.; et al. Hydrogen-rich saline protects against liver injury in rats with obstructive jaundice. Liver Int. 2010, 30, 958-968. [CrossRef] [PubMed]

14. Zhai, X.; Chen, X.; Lu, J.; Zhang, Y.; Sun, X.; Huang, Q.; Wang, Q. Hydrogen-rich saline improves nonalcoholic fatty liver disease by alleviating oxidative stress and activating hepatic pparalpha and ppargamma. Mol. Med. Rep. 2017, 15, 1305-1312. [CrossRef] [PubMed]

15. Chen, X.; Zuo, Q.; Hai, Y.; Sun, X.J. Lactulose: An indirect antioxidant ameliorating inflammatory bowel disease by increasing hydrogen production. Med. Hypotheses 2011, 76, 325-327. [CrossRef] [PubMed] 
16. Zhai, X.; Chen, X.; Shi, J.; Shi, D.; Ye, Z.; Liu, W.; Li, M.; Wang, Q.; Kang, Z.; Bi, H.; et al. Lactulose ameliorates cerebral ischemia-reperfusion injury in rats by inducing hydrogen by activating nrf2 expression. Free Radic. Biol. Med. 2013, 65, 731-741. [CrossRef] [PubMed]

17. Chen, X.; Zhai, X.; Shi, J.; Liu, W.W.; Tao, H.; Sun, X.; Kang, Z. Lactulose mediates suppression of dextran sodium sulfate-induced colon inflammation by increasing hydrogen production. Dig. Dis. Sci. 2013, 58, 1560-1568. [CrossRef] [PubMed]

18. Hai, Y.; Hong, Y.; Wang, Q.; Liu, X.; Li, D. Lactulose mediates suppression of dextran sulfate sodium-induced colon inflammation. J. Med. Coll. PLA 2013, 28, 65-79. [CrossRef]

19. Yu, J.; Zhang, W.; Zhang, R.; Ruan, X.; Ren, P.; Lu, B. Lactulose accelerates liver regeneration in rats by inducing hydrogen. J. Surg. Res. 2015, 195, 128-135. [CrossRef] [PubMed]

20. Zhai, Y.; Zhou, X.; Dai, Q.; Fan, Y.; Huang, X. Hydrogen-rich saline ameliorates lung injury associated with cecal ligation and puncture-induced sepsis in rats. Exp. Mol. Pathol. 2015, 98, 268-276. [CrossRef] [PubMed]

21. Guerra-Ordaz, A.A.; Gonzalez-Ortiz, G.; La Ragione, R.M.; Woodward, M.J.; Collins, J.W.; Perez, J.F.; Martin-Orue, S.M. Lactulose and lactobacillus plantarum, a potential complementary synbiotic to control postweaning colibacillosis in piglets. Appl. Environ. Microbiol. 2014, 80, 4879-4886. [CrossRef] [PubMed]

22. Liu, C.; Kurokawa, R.; Fujino, M.; Hirano, S.; Sato, B.; Li, X.K. Estimation of the hydrogen concentration in rat tissue using an airtight tube following the administration of hydrogen via various routes. Sci. Rep. 2014, 4, 5485. [CrossRef] [PubMed]

23. Hayashida, K.; Sano, M.; Ohsawa, I.; Shinmura, K.; Tamaki, K.; Kimura, K.; Endo, J.; Katayama, T.; Kawamura, A.; Kohsaka, S.; et al. Inhalation of hydrogen gas reduces infarct size in the rat model of myocardial ischemia-reperfusion injury. Biochem. Biophys. Res. Commun. 2008, 373, 30-35. [CrossRef] [PubMed]

24. Mao, Y.F.; Zheng, X.F.; Cai, J.M.; You, X.M.; Deng, X.M.; Zhang, J.H.; Jiang, L.; Sun, X.J. Hydrogen-rich saline reduces lung injury induced by intestinal ischemia/reperfusion in rats. BBRC 2009, 381, 602-605. [CrossRef] [PubMed]

25. Shimouchi, A.; Nose, K.; Shirai, M.; Kondo, T. Estimation of molecular hydrogen consumption in the human whole body after the ingestion of hydrogen-rich water. Adv. Exp. Med. Biol. 2012, 737, 245-250. [CrossRef] [PubMed]

26. Doll, S.; Danicke, S.; Ueberschar, K.H.; Valenta, H.; Schnurrbusch, U.; Ganter, M.; Klobasa, F.; Flachowsky, G. Effects of graded levels of fusarium toxin contaminated maize in diets for female weaned piglets. Arch. Anim. Nutr. 2003, 57, 311-334. [CrossRef]

27. Cheng, Y.H.; Weng, C.F.; Chen, B.J.; Chang, M.H. Toxicity of different fusarium mycotoxins on growth performance, immune responses and efficacy of a mycotoxin degrading enzyme in pigs. Anim. Res. 2006, 55, 579-590. [CrossRef]

28. Gibson, G.R.; Scott, K.P.; Rastall, R.A.; Tuohy, K.M.; Hotchkiss, A.; Dubert-Ferrandon, A.; Gareau, M.; Murphy, E.F.; Saulnier, D.; Loh, G.; et al. Dietary prebiotics: Current status and new definition. Food Sci. Technol. Bull. Funct. Foods 2010, 7, 1-19. [CrossRef]

29. Guerra-Ordaz, A.A.; Molist, F.; Hermes, R.G.; Gómez de Segura, A.; La Ragione, R.M.; Woodward, M.J.; Tchorzewska, M.A.; Collins, J.W.; Pérez, J.F.; Martín-Orúe, S.M. Effect of inclusion of lactulose and lactobacillus plantarum on the intestinal environment and performance of piglets at weaning. Anim. Feed Sci. Technol. 2013, 185, 160-168. [CrossRef]

30. Panesar, P.S.; Kumari, S. Lactulose: Production, purification and potential applications. Biotechnol. Adv. 2011, 29, 940-948. [CrossRef] [PubMed]

31. Krueger, M.; Schroedl, W.; Isik, W.; Lange, W.; Hagemann, L. Effects of lactulose on the intestinal microflora of periparturient sows and their piglets. Eur. J. Nutr. 2002, 41 (Suppl. 1), 126-131. [CrossRef] [PubMed]

32. Maresca, M. From the gut to the brain: Journey and pathophysiological effects of the food-associated trichothecene mycotoxin deoxynivalenol. Toxins 2013, 5, 784-820. [CrossRef] [PubMed]

33. Moran, T.H.; Smedh, U.; Kinzig, K.P.; Scott, K.A.; Knipp, S.; Ladenheim, E.E. Peptide yy(3-36) inhibits gastric emptying and produces acute reductions in food intake in rhesus monkeys. Am. J. Physiol. Regul. Integr. Comp. Physiol. 2005, 288, R384-R388. [CrossRef] [PubMed] 
34. Wu, W.; Zhou, H.R.; He, K.; Pan, X.; Sugita-Konishi, Y.; Watanabe, M.; Zhang, H.; Pestka, J.J. Role of cholecystokinin in anorexia induction following oral exposure to the 8-ketotrichothecenes deoxynivalenol, 15-acetyldeoxynivalenol, 3-acetyldeoxynivalenol, fusarenon $x$, and nivalenol. Toxicol. Sci. 2014, 138, 278-289. [CrossRef] [PubMed]

35. Flannery, B.M.; Clark, E.S.; Pestka, J.J. Anorexia induction by the trichothecene deoxynivalenol (vomitoxin) is mediated by the release of the gut satiety hormone peptide yy. Toxicol. Sci. 2012, 130, 289-297. [CrossRef] [PubMed]

36. Wu, W.D.; Bates, M.A.; Bursian, S.J.; Flannery, B.; Zhou, H.R.; Link, J.E.; Zhang, H.B.; Pestka, J.J. Peptide yy3-36 and 5-hydroxytryptamine mediate emesis induction by trichothecene deoxynivalenol (vomitoxin). Toxicol. Sci. 2013, 133, 186-195. [CrossRef] [PubMed]

37. Shaw, A.M.; Irani, B.G.; Moore, M.C.; Haskell-Luevano, C.; Millard, W.J. Ghrelin-induced food intake and growth hormone secretion are altered in melanocortin 3 and 4 receptor knockout mice. Peptides 2005, 26, 1720-1727. [CrossRef] [PubMed]

38. Matsumoto, A.; Yamafuji, M.; Tachibana, T.; Nakabeppu, Y.; Noda, M.; Nakaya, H. Oral 'hydrogen water' induces neuroprotective ghrelin secretion in mice. Sci. Rep. 2013, 3, 3273. [CrossRef] [PubMed]

39. Frankic, T.; Pajk, T.; Rezar, V.; Levart, A.; Salobir, J. The role of dietary nucleotides in reduction of DNA damage induced by $\mathrm{t}-2$ toxin and deoxynivalenol in chicken leukocytes. Food Chem. Toxicol. 2006, 44, 1838-1844. [CrossRef] [PubMed]

40. Frankic, T.; Salobir, J.; Rezar, V. The effect of vitamin e supplementation on reduction of lymphocyte DNA damage induced by t-2 toxin and deoxynivalenol in weaned pigs. Anim. Feed Sci. Technol. 2008, 141, 274-286. [CrossRef]

41. Xiao, H.; Wu, M.M.; Tan, B.E.; Yin, Y.L.; Li, T.J.; Xiao, D.F.; Li, L. Effects of composite antimicrobial peptides in weanling piglets challenged with deoxynivalenol: I. Growth performance, immune function, and antioxidation capacity. J. Anim. Sci. 2013, 91, 4772-4780. [CrossRef] [PubMed]

42. Jiang, S.Z.; Yang, Z.B.; Yang, W.R.; Gao, J.; Liu, F.X.; Broomhead, J.; Chi, F. Effects of purified zearalenone on growth performance, organ size, serum metabolites, and oxidative stress in postweaning gilts. J. Anim. Sci. 2011, 89, 3008-3015. [CrossRef] [PubMed]

43. Wang, D.F.; Zhang, N.Y.; Peng, Y.Z.; Qi, D.S. Interaction of zearalenone and soybean isoflavone in diets on the growth performance, organ development and serum parameters in prepubertal gilts. J. Anim. Physiol. Anim. Nutr. 2012, 96, 939-946. [CrossRef] [PubMed]

44. Li, J.; Wang, C.; Zhang, J.H.; Cai, J.-M.; Cao, Y.-P.; Sun, X.-J. Hydrogen-rich saline improves memory function in a rat model of amyloid-beta-induced alzheimer's disease by reduction of oxidative stress. Brain Res. 2010, 1328, 152-161. [CrossRef] [PubMed]

45. Wang, C.; Li, J.; Liu, Q.; Yang, R.; Zhang, J.H.; Cao, Y.P.; Sun, X.J. Hydrogen-rich saline reduces oxidative stress and inflammation by inhibit of jnk and nf-kappab activation in a rat model of amyloid-beta-induced alzheimer's disease. Neurosci. Lett. 2011, 491, 127-132. [CrossRef] [PubMed]

46. Ferrer, M.; Manyes, L.; Manes, J.; Meca, G. Influence of prebiotics, probiotics and protein ingredients on mycotoxin bioaccessibility. Food Funct. 2015, 6, 987-994. [CrossRef] [PubMed]

47. Florent, C.; Flourie, B.; Leblond, A.; Rautureau, M.; Bernier, J.J.; Rambaud, J.C. Influence of chronic lactulose ingestion on the colonic metabolism of lactulose in man (an in vivo study). J. Clin. Investig. 1985, 75, 608-613. [CrossRef] [PubMed]

48. Liu, S.; Duan, Y.; Ge, C.; Chen, C.; Zhou, M. Functional analysis of the beta2 -tubulin gene of fusarium graminearum and the beta-tubulin gene of botrytis cinerea by homologous replacement. Pest Manag. Sci. 2013, 69, 582-588. [CrossRef] [PubMed]

49. National Research Council (U.S.). Committee on Nutrient Requirements of Swine. In Nutrient Requirements of Swine, 11th ed.; National Academies Press: Washington, DC, USA, 2012; pxvii; 4400p.

50. Ji, F.; Xu, J.; Liu, X.; Yin, X.; Shi, J. Natural occurrence of deoxynivalenol and zearalenone in wheat from Jiangsu Province, China. Food Chem. 2014, 157, 393-397. [CrossRef] [PubMed] 
51. Zheng, W.; Hou, Y.; Yao, W. Lactulose increases equol production and improves liver antioxidant status in barrows treated with daidzein. PLoS ONE 2014, 9, e93163. [CrossRef] [PubMed]

52. Sun, H.; Chen, L.; Zhou, W.; Hu, L.; Li, L.; Tu, Q.; Chang, Y.; Liu, Q.; Sun, X.; Wu, M.; et al. The protective role of hydrogen-rich saline in experimental liver injury in mice. J. Hepatol. 2011, 54, 471-480. [CrossRef] [PubMed] 